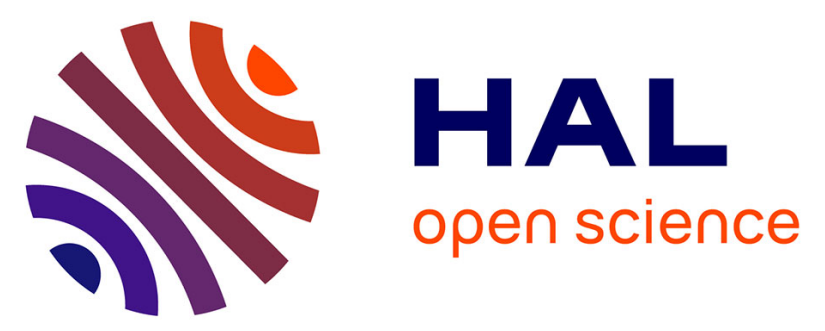

\title{
Corrigendum to "Relationships between human activity and biodiversity in Europe at the national scale: Spatial density of human activity as a core driver of biodiversity erosion" [Ecol. Indicators 90 (2018) 356-365]
}

Frédéric Gosselin, Jean-Marc Callois

\section{To cite this version:}

Frédéric Gosselin, Jean-Marc Callois. Corrigendum to "Relationships between human activity and biodiversity in Europe at the national scale: Spatial density of human activity as a core driver of biodiversity erosion" [Ecol. Indicators 90 (2018) 356-365]. Ecological Indicators, 2019, 99, pp.394-395. 10.1016/j.ecolind.2018.12.026 . hal-02499734

\section{HAL Id: hal-02499734 \\ https://hal.science/hal-02499734}

Submitted on 5 Mar 2020

HAL is a multi-disciplinary open access archive for the deposit and dissemination of scientific research documents, whether they are published or not. The documents may come from teaching and research institutions in France or abroad, or from public or private research centers.
L'archive ouverte pluridisciplinaire HAL, est destinée au dépôt et à la diffusion de documents scientifiques de niveau recherche, publiés ou non, émanant des établissements d'enseignement et de recherche français ou étrangers, des laboratoires publics ou privés. 
Corrigendum to: Relationships between human activity and biodiversity in

Europe at the national scale: spatial density of human activity as a core driver

This corrigendum aims to correct the first three columns of Table 3 in Gosselin and Callois (2018), which was based on an erroneous program to calculate marginal Leave-one-out Information Criteria (LOOIC). Table 1 in the present paper replaces this previous Table 3. We discuss why the new results are more in agreement with the other results of Gosselin and Callois (2018) and why the marginal version of the LOOIC appears better than the conditional version.

\section{Statistical methods}

Here, the statistical models are the same as the ones in Gosselin and Callois (2018). They are Bayesian models which incorporate country random effects when observations were repeated in each country (for the two State Indicators and the Response Indicator), and which have a beta-binomial probability distribution for the two State Indicators and a zero-inflated beta distribution for the Response Inidcator and the two Pressure indicators. The zero-inflated beta distribution is a direct subproduct of the zero-inflated cumulative beta distribution that Herpigny and Gosselin (2015; MTUnlimited2 version) proposed to analyze plant cover class data. Indeed, we used statistical methods with a priori relevant probabilistic properties relative to our data. Based on the lessons 
27 learned on partly similar data from Gosselin (2015), we paid careful attention to the potential over-

28 dispersion of data as well as to the inclusion of random country effects.

29 We compared the models with the Leave-one-out Information Criterion (LOOIC) developed by

30 Vehtari et al. (2016). For State and Response indicators, we used the marginal version of the LOOIC

31 - i.e. the LOOIC integrated over the random effects -, for reasons discussed by Millar (2009, 2017),

32 and because the country random effect introduced a number of parameters which was of the same

33 order of magnitude as the number of observations. We calculated the marginal versions of the LOOIC

34 for 10,000 parameter values randomly drawn from the MCMC output by taking the mean of

35 probabilities of the observed data grouped by country over 1,000 random draws of the country

36 random effect. The original code in Gosselin and Callois (2018) was erroneous in that it did not take

37 into account the dependence between observations in the same country (i.e. the mean probability of

38 each observation was taken instead of the mean probability after grouping the observations of each

39 country). The new calculations used here correct this previous error.

40

${ }_{41}$ Results

42

\begin{tabular}{|l|l|l|l|l|l|}
\hline Model name & Extinct & Threatened & Protected & SEAL & iSEAL \\
species & species & Areas & & \\
\hline Null & 15.91 & 13.10 & $\underline{\mathbf{0 . 0 0}}$ & 46.86 & 19.93 \\
\hline eco & $\mathbf{4 . 3 7}$ & 11.66 & 7.34 & 18.26 & $\underline{\mathbf{0 . 0 0}}$ \\
\hline leco & $\mathbf{2 . 8 8}$ & $\mathbf{1 . 7 2}$ & 6.47 & $\underline{\mathbf{0 . 0 0}}$ & $\mathbf{0 . 6 1}$ \\
\hline
\end{tabular}




\begin{tabular}{|c|c|c|c|c|c|}
\hline Kuznets & 15.56 & 12.00 & 6.02 & 42.09 & 17.91 \\
\hline 1Kuznets & 17.35 & 13.40 & 5.27 & 48.01 & 19.70 \\
\hline Kuznetsa & $\underline{0.00}$ & $\underline{\mathbf{0 . 0 0}}$ & 10.27 & 12.95 & 4.80 \\
\hline 1Kuznetsa & 0.42 & 1.89 & 3.67 & 6.58 & 5.03 \\
\hline demo & 5.16 & 10.51 & 11.94 & 17.16 & 0.82 \\
\hline 1demo & 3.07 & 4.43 & 2.54 & 1.41 & 3.57 \\
\hline FC & 1.91 & 4.05 & 4.45 & 40.82 & 22.14 \\
\hline SC & 12.64 & 9.83 & 6.16 & 52.64 & 24.38 \\
\hline NGOs & 14.72 & 15.28 & 5.24 & 39.10 & 15.05 \\
\hline ERV & 11.00 & 14.11 & 3.12 & 44.85 & 22.32 \\
\hline
\end{tabular}

43 Table 1. Statistical comparison of models. Difference in Leave-one-out Information Criterion

44 (LOOIC) values with the LOOIC of the best model fitted for the different explanatory models (by

45 column). The lower the LOOIC, the better the model. The best model is underlined and models with a

46 LOOIC relatively close to the best model-i.e. within six units of the best model - are in bold (as

47 suggested in Millar, 2009). Only the models pertaining to the same target variable (models within the

48 same column) are comparable. See Tables 1 and 2 in Gosselin and Callois (2018) for the content of

49 the models. For the three first columns, the marginal version of the LOOIC is reported (see text). 


\section{Discussion}

52 The new corrected values of the marginal LOOIC in Table 3 do not change any of the practical 53 conclusions in Gosselin and Callois (2018). However, they are more coherent with the levels of 54 significance of the estimators (Tables 4 to 7 in Gosselin and Callois 2018) than were the previous the Null model. the Null model. significance of the most significant effects of explanatory variables were overall less significant for the Proportion of Extinct and Threatened species (Tables 4 and 5 in Gosselin and Callois 2018) than for the proportion of Sealed area or the dynamics of this proportion (Tables 6 and 7 in Gosselin and Callois 2018). Yet, previous differences in LOOIC values with the null model had indicated stronger differences for Extinct and Threatened species with respect to the dynamics in the proportion of Sealed areas (Table 3 in Gosselin and Callois 2018).

The new model comparison results presented herein in Table 1 establish an ordering that is more in line with the significance of the effects. This behavior is in agreement with McQuarrie and Tsai's (1999) results; for orthogonal regressions, they showed a direct link between the statistical significance of the effects of models and their Akaike Information Criterion (AIC), a criterion close to LOOIC for such simple settings. Our settings are not very different from orthogonal regressions since we mostly chose models with not too much correlated explanatory variables. The fact that the new marginal LOOIC are more coherent with the levels of significance of the estimators than were the previous values obtained is therefore welcome. In the case of the SC model for the proportion of Threatened species (Table 1), the results for marginal LOOIC shown in Table 1 are also more satisfactory than the conditional LOOIC results presented in Table SM1 (Supplementary material): given the two significant estimators involved in the model (Table 5 in Gosselin and Callois 2018), marginal LOOIC indicates that the SC model is better than the Null model, qualitatively in agreement with McQuarrie and Tsai (1999)'s results, while conditional LOOIC indicates that it is not as good as 
77 Acknowledgements. This research was supported by the French ministry in charge of Ecology

78 through the DEB-Irstea convention (Action 16). We warmly thank Victoria Moore for her help in

79 improving the clarity and style of the English manuscript.

80

81 References:

82 Gosselin, F., 2015. Reevaluating Europe's other debt with improved statistical tools. Biodiv. Cons.

$8324,205-211$.

84 Gosselin, F., Callois, J.-M., 2018. Relationships between human activity and biodiversity in Europe at

85 the national scale: Spatial density of human activity as a core driver of biodiversity erosion. Ecol.

86 Indicators 90, 356-365.

87 Herpigny, B., Gosselin, F., 2015. Analyzing plant cover class data quantitatively: customized

88 cumulative zero-inflated beta distributions show promising results. Ecol. Informatics 26, 18-26.

89 McQuarrie, A., and Tsai, C.L. 1999. Model selection in orthogonal regression. Statistics \& Probability

90 Letters 45(4):341-349.

91 Millar, R.B. 2009. Comparison of hierarchical bayesian models for overdispersed count data using

92 DIC and Bayes' factors. Biometrics 65, 962-969.

93 Millar, R.B., 2017. Conditional vs marginal estimation of the predictive loss of hierarchical models

94 using WAIC and cross-validation. Statistics and Computing 28, 375-385. 